\title{
MEMÓRIAS QUE ATRAVESSAM A MORTE: AS RECORDAÇÕES DA VIOLÊNCIA CONTRA A MULHER EM GAROTAS MORTAS, DE SELVA ALMADA
}

LIMA, Maria Izabella Souza de ${ }^{1}$

Resenha do livro Garotas Mortas, de Selva Andrade. Tradução de Sérgio Molina. São Paulo: Todavia, 2018, (eBook Kindle).

O retrato da realidade feminina, por muitas vezes, é cruel e frio. Sobretudo em zonas periféricas, rurais e com pouco acesso à informação, o silenciamento é o preço a se pagar. O feminicídio ocorre em todo o mundo, mas mesmo assim, poucos são os casos que são julgados e os culpados condenados. Deste modo, a imprensa tem um papel fundamental na divulgação desses dados e casos também. A obra Garotas Mortas me sensibiliza como pesquisadora, pois apresenta vários pontos de intersecção com o cenário descrito acima. Escrito por Selva Almada, composto em 2014, só foi publicado no Brasil, pela editora Todavia, em 2018. Em função disso, este texto irá abordar não só os aspectos marcantes do livro, mas também mostrará como o movimento de conceder fala às garotas mortas por parte da autora é uma maneira de manter a memória e de buscar justiça para elas.

Foi então que o rádio deu a notícia. Eu não estava prestando atenção, mas mesmo assim a ouvi bem claramente. Naquela mesma madrugada, em San José, uma cidadezinha a vinte quilômetros dali, uma adolescente tinha sido assassinada em sua própria cama, enquanto dormia. Meu pai e eu continuamos em silêncio. (ALMADA, 2018, p. 9)

\footnotetext{
${ }^{1}$ Resenha apresentada à disciplina de "Literatura, Cultura e Mídia"; Mestranda em Teoria e História Literária pela Unicamp; Professora particular e pesquisadora; m.izabella.souzalima@gmail.com - Bolsista CAPES. 


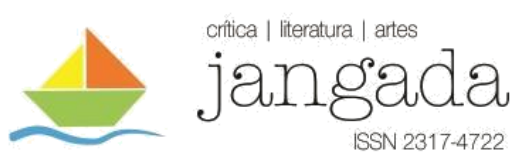

Andrea Danne, 19, assassinada com uma punhalada no coração enquanto dormia em sua casa. María Luisa Quevedo, 15, estuprada, estrangulada e abandonada em local baldio. Sarita Mundín, 20, desaparecida por meses até seus ossos aparecerem presos em galhos perto de um rio. (Ibid., 2018, p. 16)

O livro se organiza em 11 capítulos e um epílogo, e apresenta narração ora em primeira pessoa (voz autoral), ora em terceira. Possui um ar investigativo e traça pontos entre violência doméstica, exploração sexual de meninas e mulheres e a exposição de vida das mulheres na recém democratizada Argentina. Inicia e termina com uma lista de mortes femininas, além de buscar por mais informações sobre três feminicídios. Sendo eles respectivamente: Andrea Danne (19), María Luisa Quevedo (15) e Sarita Mundín (20), classificados como "crimes pequenos" na época que ocorreram, nos anos 80. As histórias das jovens, misturadas às da autora, são contadas para fazer justiça a esses crimes impunes em particular e a todos os feminicídios de modo geral.

Durante mais de vinte anos, Andrea esteve por perto. Voltava de quando em quando com a notícia de outra mulher morta. Iam se acumulando os nomes que apareciam a conta-gotas nas manchetes dos jornais de circulação nacional: María Soledad Morales, Gladys McDonald, Elena Arreche, Adriana e Cecilia Barreda, Liliana Tallarico, Ana Fuschini, Sandra Reitier, Carolina Aló, Natalia Melman, Fabiana Gandiaga, María Marta García Belsunce, Marela Martínez, Paulina Lebbos, Nora Dalmasso, Rosana Galliano. Cada uma delas me levava a pensar em Andrea e em seu assassinato impune. (Ibid., 2018, p. 10)

Essas "chicas vivas y cuerpo deseantes" (OVIEDO, 2015, p. 4) seguiram, de alguma maneira, a jornalista por toda a sua vida, reaparecendo em suas memórias a cada novo assassinato. É quase que impossível não relacionar o destino das garotas relatadas no romance com a realidade atual. Segundo dados do Ministério da Saúde compilados pelo Atlas da Violência, lançados em 2019 pelo Ipea e pelo Fórum Brasileiro de Segurança Pública, 4.936 feminicídios foram registrados, sendo em média 13 por dia. Desse número, 66\% são mulheres pretas, muitas vezes pobres e periféricas. Por fim, constata-se que os nomes aumentam e as histórias se repetem.

De acordo com Sigmund Freud em Escritores criativos e devaneios (1974), o trabalho mental se vincula com uma impressão mental, em que por meio de algum gatilho retrocede uma 


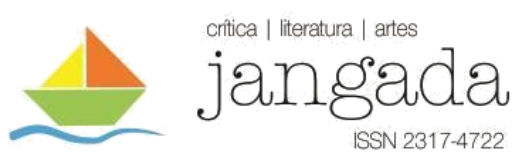

lembrança da infância que pode desencadear um desejo, e que o passado, o presente e o futuro são unidos por esse fio. (FREUD, 1974, p. 138). Assim, nas páginas iniciais do livro, Almada comenta sobre a insegurança que sentiu quando nova, e estabelece a relação dos três casos não resolvidos consigo, pois foram as primeiras recordações de violência que atravessaram sua infância e adolescência. E essa sensação é percebida em outros momentos ao longo da obra (CABRAL, 2016, p. 4). O fato de uma memória infantil repercutir a ponto de ser escrita dialoga com o pensamento de Freud (1974). Reiterando que a realização da obra criativa revela elementos da "ocasião motivadora do presente" — os assassinatos das mulheres — com a "lembrança antiga" — os três casos sem solução. (Ibid., 1974, p. 141).

Por meio da narrativa de Selva Almada percebe-se que ela traça um perfil de suas personagens, até mesmo ouve as suas vozes - até mesmo com a ajuda de uma cartomante ato "simbólico", pois o feminicídio é um silenciamento. Apura as circunstâncias das mortes ou desaparecimentos e numa tentativa de compreender porque foram casos inconclusivos. Além de visitar as cidades em que as garotas viviam, conversava com parentes e conhecidos numa tentativa de reconstruir os últimos momentos das vítimas. María Celeste Cabral (2016, p. 5) em "De investigadora a huesera: Chicas muertas de Selva Almada y las formas de narrar el femicidio en el interior” afirma: “[...] La literatura se transforma en el discurso social que da por saldado el debate acerca del uso de la primera persona para referirse a la experiencia del pasado reciente, y muestra las potencialidades de la exploración de las huellas del impacto de la violencia en el plano subjetivo."

Há, também, um tom testemunhal, presente o tempo todo durante o livro, utilizado através da reconstituição da vida das meninas e a incorporação de fatos marcantes vividos pela autora. No capítulo três, em um encontro com a cigana é contada a história de La Huesera, a Mulher dos Ossos, uma senhora que recolhe ossos de vários animais, e que, de acordo com a lenda após juntar todos os ossos especificamente, dos lobos, ao pôr a última peça no lugar, a figura resplandece diante dos olhos da mulher e sai a correr livre. E como forma de assimilar o seu propósito ao empreender essa jornada em busca de justiça, e afirma que possivelmente “[...] seja esta a sua missão: recolher os ossos das garotas, armá-las, dar-lhes voz e depois deixá-las correr livremente para onde tiverem que ir." (ALMADA, 2018, p. 23)

\footnotetext{
${ }^{2}$ Trad.: "[...] A literatura torna-se o discurso social que dá como certo o debate sobre o uso da primeira pessoa para se referir à experiência do passado recente, e mostra a potencialidade de explorar os traços do impacto da violência no plano subjetivo."
} 
Em seguida, há uma série de relatos a respeito de violências sofridas por mulheres próximas de Selva, sua mãe, uma vizinha, colegas: "Não me lembro de nenhuma conversa específica sobre violência de gênero, nem que minha mãe fizesse alguma advertência expressa sobre o tema. Mas ele sempre estava presente: quando falávamos da Marta, a vizinha espancada pelo marido, a qual por sua vez descia o braço nos filhos [...]" (Ibid., 2018, 1. 24)

Assim, a investigação presente no texto é literária, a autora busca entender o porquê de uma mulher ser morta por ser mulher, e olha para o quão "banais" as palavras do título "garota" e "morta" se tornaram na sociedade, e desconstrói a figura do agressor, imaginava-se que “[...] estupradores eram sempre homens desconhecidos que agarravam uma mulher e a levavam para o mato, ou que entravam em sua casa forçando uma porta. [...]. Nunca ninguém falou que você podia ser estuprada pelo marido, pelo pai, pelo irmão, pelo vizinho, pelo professor. Por um homem em quem você tem toda a confiança." (ALMADA, 2018, 1. 24/25)

Shoshana Felman, em seu livro $O$ inconsciente jurídico (2014), especificamente no capítulo intitulado: "Formas de cegueira judicial, ou a evidência do que não pode ser visto", irá abordar como a justiça pode de alguma maneira legitimar o feminicídio por meio do estudo do caso de O. J. Simpson e do romance A sonata de Kreutzer, de Liev Tolstói, publicado em 1889. O ponto chave dos dois casos é que ambos assassinaram suas esposas e foram absolvidos por isso. Nas partes finais do capítulo, Felman tece relações que são possíveis à literatura em casos como os explicitados por Almada, em que o fazer literário, explicado ou compelido, é um meio específico de testemunho, e os autores o fazem quando sentem ou sabem

[...] que no tribunal da história (e, agora acrescentarei, num tribunal de justiça) a evidência falhará ou deixará a desejar; quando sabem que outros tipos de testemunhos, por diferentes razões, não obterão êxito ou que existiram acontecimentos que, por diferentes razões, não serão evidenciados. [...] mais profundamente, quando sabem ou sentem que o conhecimento, embora disponível, não é capaz de tornar-se eloquente, que $a$ informação não pode tornar-se importante. (FELMAN, 2014, p. 129 , grifos da autora)

Como mencionado anteriormente, há uma necessidade de escrita não só para reconstituir a vida das garotas, mas também como maneira de libertá-las por meio da vocalização de tudo o que lhes aconteceu. Se, pelos meios judiciais, não foi possível punir os devidos culpados, é 


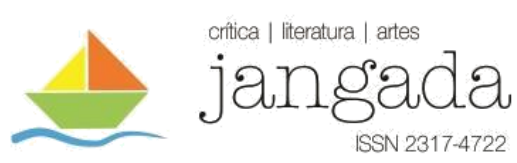

preciso que a literatura possa fazê-lo, expondo fatos, tal qual diz Felman em seu texto, e que os tribunais deixaram escapar (FELMAN, 2014, p. 128). Por isso vale ressaltar o artigo "Imagens precárias: inscrições tênues de violência ditatorial no Brasil” de Márcio Seligmann-Silva (2014, p. 24); nele o autor discute a vinculação na memória cultural dos fatos violentos que ocorreram na ditadura civil-militar no Brasil e traz uma citação que se relaciona muito com a escrita de Almada neste romance, pois nele o "[...] tempo do trauma é repetitivo e fragmentado. A memória dos fatos, mesmo que recentes, faz parte de um ruminar melancólico. O texto é descritivo, com poucas metáforas ou outras figuras de estilo".

Assim, a narrativa se constitui como uma trama, por meio de um ir e vir mesclando dados autobiográficos com as reconstituições das histórias, junto de outras histórias que lhe foram repassadas por sua mãe. Misturando o espaço público e privado (íntimo), e também o da sociedade como um todo, percebe-se o testemunho-narrativa da autora com a demanda de justiça. Com isso, resgatar os últimos momentos de María Luisa, Andrea e Sarita é também recuperar a memória de diversas mulheres silenciadas pela misoginia. A Dra. María Verónica Elizondo Oviedo $(2015,1$. 6) cita Jacques Derrida ao falar do papel documental da obra de Selva Almada, da importância do valor patrimonial de uma obra estar associada à sociedade que a gera, e também da necessidade de se proteger documentos para evitar seu desaparecimento.

Por fim, a autora de Garotas Mortas deseja que os culpados pelos assassinatos sejam responsabilizados e continua “(...) acho que o que nós precisamos é reconstruir o jeito como o mundo olhava para elas. Se conseguirmos saber como elas eram vistas, como eram olhadas, vamos saber qual era o olhar que elas tinham sobre o mundo, entende?” (ALMADA, 2018, p. 47). A sua relação com a morte é curiosa, uma vez que esta a fascinava e a levava a ir ao cemitério, enfeitar com crisântemos e dálias os túmulos. Imaginar a vida que elas poderiam ter tido também auxilia nesse processo de reconstituição da vida dessas garotas (ALMADA, 2018, p. 70).

Não só isso, mas também as histórias de várias mulheres que ouviu durante toda a sua vida motivaram Almada a compor essa narrativa de testemunho e de justiça. Pois, ao contrário das dezenas de mulheres que se foram até o momento de sua escrita, ela continuava viva e, talvez por isso, tenha tomado para si a tarefa de (re)escrever essas vivências. De acordo com Felman (2014, p. 131) “[...]. Falamos para evitar a culpa. Falamos para evitar a dor. Usamos o discurso para nos proteger. Profundamente, falamos para ter esperança. [...]”. Portanto, é preciso enxergar essas vítimas, dar-lhes voz para não as esquecer, é necessário que se entenda qual era a estrutura que as rodeava e que as matou. Reconstruir essas memórias e experiências, 
por mais dolorosas que sejam, foi a forma que Selva encontrou de colocar a voz dessas meninas no mundo. Uma maneira de conscientizar e tentar salvar outras mulheres.

Seguimos caminhando, mais apertadas uma contra a outra, os braços pegajosos por causa do calor. $\mathrm{O}$ vento norte esfregava entre si as folhas ásperas dos pés de milho, fazia vibrar os talos maduros, tirando um som ameaçador que, apurando o ouvido, também podia ser a música de uma pequena vitória. (Ibid, 2018, p. 76).

\section{REFERÊNCIAS BIBLIOGRÁFICAS}

ALMADA, S. Garotas Mortas. Tradução de Sérgio Molina. São Paulo: Todavia, 2018. eBook Kindle.

ATLAS DE VIOLÊNCIA 2019. Disponível em:

$<$ https://www.ipea.gov.br/portal/index.php?option=com_content\&view=article\&id=34784>

Acesso em: 06 de mar. 2020.

CABRAL, M. C. De investigadora a huesera: Chicas muertas de Selva Almada y las formas de narrar el femicidio en el interior. IV JORNADAS DEL CENTRO INTERDISCIPLINARIO DE INVESTIGACIONES EN GÉNERO, Abril de 2016, sem paginação, Ensenada, Argentina. EN: Actas. Ensenada: Universidad Nacional de La Plata. Facultad de Humanidades y Ciencias de la Educación. Centro Interdisciplinario de Investigaciones en Género. En Memoria Académica. Disponível em: 〈http://www.memoria.fahce.unlp.edu.ar/trab_eventos/ev.9972/ev.9972.pdf > Acesso em: 05 de jul. 2020.

FELMAN. S. Formas de cegueira judicial, ou a evidência do que não pode ser visto. In: $O$ inconsciente jurídico. São Paulo: EDIPRO, 2014.

FREUD, S. (1908). Escritores criativos e devaneios. In: FREUD, S. Edição standard brasileira das obras psicológicas de Sigmund Freud. Rio de Janeiro: Imago, 1974. Tradução de J. Salomão. Vol. 9.

IDOETA, P.A. BBc: Atlas da Violência: Brasil tem 13 homicídios de mulheres por dia, e maioria das vítimas é negra. BBC NEWS - São Paulo (05/06/2019). Disponível em: <https://www.bbc.com/portuguese/brasil-48521901> Acesso em: 08 de mar. 2020.

OVIEDO, M.V.E. Femicidio y exhumación del archivo en Chicas Muertas de Selva Amada. IV CONGRESO INTERNACIONAL CUESTIONES CRÍTICAS 30 DE SEPTIEMBRE, Jangada | nr. 16, jun/dez, 2020 | ISSN 2317-4722 
Octubre de 201, sem paginação, Rosario, Argentina. EN: Centro de Estudios de Literatura Argentina; Centro de estudios en Teoría y Crítica Literaria: Universidad Nacional de Rosario. PINHEIRO, L. Selva Almada: Sobre contar a história comum das Garotas Mortas. Valkirias: São Paulo (26/07/2018). Disponível em: <http://valkirias.com.br/selva-almada-sobre-contar-ahistoria-comum-das-garotas-mortas/> Acesso em: 05 de jul. 2020.

SELIGMANN-SILVA, M. Imagens precárias: inscrições tênues de violência ditatorial no Brasil. In: Estudos de Literatura Brasileira Contemporânea, n. 43, p. 13-34, 14 maio 2014. Disponível em:<https://periodicos.unb.br/index.php/estudos/article/view/9942/8782> Acesso em: 17 de ago. 2020. 